\title{
Motricidade, Corporeidade e Complexidade: diálogos a partir do hemisfério sul
}

\author{
Motricity, Corporeality and Complexity: dialogues from the southern hemisphere
}

Motricidad, Corporeidad e Complejidad: diálogos desde hemisferio sur

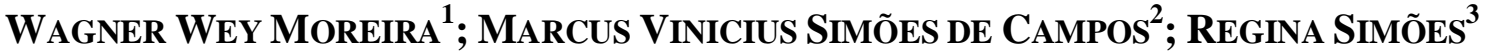 \\ UNiversidade Federal do TriângUlo Mineiro, UFTM, Uberaba-MG, Brasil \\ UniVERSIDAde ESTADUAL DE CAMPINAS, UNICAMP, CAMPINAS-SP, BRASIL
}

\begin{abstract}
RESUMO
O presente escrito tem por objetivo aliar os temas Motricidade, Corporeidade e Complexidade, todos atrelados ao sentido educacional formal, mostrando a importância do trato desses temas por pesquisadores e professores, fato esse que permite alterar o conceito de corpo na cultura e na escola. É um artigo de reflexão, centrado em pesquisa bibliográfica enfatizando: a Motricidade como possível meta-ciência ocupada em reconhecer o ser humano que se movimenta intencionalmente na direção de transcender; a Corporeidade como uma atitude a exigir valores diferentes do trato com o corpo mecânico, ainda estudado e ensinado de forma hegemônica na atualidade; a Complexidade como nova forma de perspectivar a vida e os pressupostos axiológicos nela contidos. Palavras-chave: Motricidade. Corporeidade. Complexidade.
\end{abstract}

\begin{abstract}
The present paper aims to evaluate the themes of Motricity, Corporeality and Complexity, all combined with the formal education sense, showing the importance of these themes for researchers and teachers, in the sense of change the current concept of body in the culture and at school. It is a reflective paper, focusing on bibliographical research emphasizing: the Motricity as a possible meta-science that recognize a human being that move intentionally to transcendence itself; the Corporeality as an attitude that require different values to deal with the mechanic body, still studied and taught in a hegemonic way today; the Complexity as a new way to envision life and the axiological assumptions contained therein.
\end{abstract}

Keywords: Motricity. Corporeality. Complexity.

\section{RESUMEN}

Este artículo tiene como objetivo combinar los temas de Motricidad, Corporeidad y Complejidad, todos vinculados al sentido educativo formal, mostrando la importancia del tratamiento de los temas por parte de investigadores y maestros, un hecho que permite cambiar el concepto de cuerpo en la cultura y la escuela. Es un artículo de reflexión, centrado en la investigación bibliográfica que enfatiza la motricidad como una posible metaciencia involucrada con el reconocimiento del ser humano que intencionalmente se mueve hacia trascender; la corporeidad como una actitud que exige diferentes valores al tratar con el cuerpo mecánico, todavía estudiada y enseñada de manera hegemónica en la actualidad; la complejidad como una nueva forma de ver la vida y los supuestos axiológicos contenidos en ella.

Palabras clave: Motricidad. Corporeidad. Complejidad.

\footnotetext{
${ }^{1}$ Professor Adjunto da UFTM. NUCORPO: Núcleo de Estudos/Pesquisas em Corporeidade e Pedagogia do Movimento. Apoio CNPq. E-mail: wmoreira@ef.uftm.edu.br

2 Doutorando da Faculdade de Educação Física da UNICAMP, Campus Campinas-SP. E-mail: camposmvs@gmail.com

${ }^{3}$ Professora Associada da UFTM. NUCORPO: Núcleo de Estudos/Pesquisas em Corporeidade e Pedagogia do Movimento. E-mail: regina.simoes@uftm.edu.br
} 


\section{INTRODUÇÃO}

Escrever, de forma associada, sobre os temas Motricidade, Corporeidade e Complexidade pressupõe, num primeiro momento, dificuldades enormes, ainda mais pensando em interculturalidade. Porém, ao detalharmos essas três dimensões contatamos pontos de aproximação o que permite a presente redação. Sem dúvida a Motricidade depende da atitude de Corporeidade e esta, por sua vez, acha-se presente de forma Complexa no contexto da interculturalidade.

Também devemos levar em conta que as três dimensões mencionadas no parágrafo anterior estão contidas, no presente trabalho, na preocupação com a educação e territorialmente imbricadas no hemisfério sul de nosso planeta.

Daí a estrutura do escrito estar formatada em abordar: a Motricidade como uma possível meta-ciência com a preocupação de elucidar a intencionalidade do ser humano que se movimenta na direção de sua transcendência; a Corporeidade como possibilidade de superação da ideia de corpo máquina ou objeto, levando-nos ao sentido de corpo sujeito produtor de história e cultura; a Complexidade, esta alocada na abordagem da Complexidade de Edgar Morin, todas relacionadas com a educação, propiciando relações de cooperação e respeito a diferentes sujeitos e culturas, preservando suas identidades, mas caminhando no sentido de buscar a unidade nas diferenças.

Em qual contexto tudo isto se insere? Na lusofonia do hemisfério sul, afinal dizem os pesquisadores que a língua portuguesa é a mais falada nesse hemisfério, com o envolvimento de mais de duzentos e quarenta e cinco milhões de pessoas. Temos, portanto, um privilégio e uma responsabilidade em produzir e em disseminar conhecimento.

\section{MOTRICIDADE: A INTENCIONALIDADE AO SE MOVIMENTAR}

Motricidade: Processo adaptativo, evolutivo e criativo de um ser práxico, carente dos outros, do mundo e da transcendência.

(Manuel Sérgio)

Não há dúvida em se afirmar que foi Manuel Sérgio o grande arquiteto do trabalho sobre Motricidade Humana para a área da Educação Física. Em suas preocupações epistemológicas junto a Faculdade de Motricidade Humana de Lisboa, enfatizava que esta deveria estudar o "[...] desenvolvimento humano através da Motricidade, pelo estudo do corpo e das suas manifestações, na interação dos processos biológicos com os valores sócio-culturais" (SERGIO, 1996, p. 15) Diz mais esse autor, apropriando-se dos escritos fenomenológicos de Merleau-Ponty, que a Motricidade propicia uma relação dinâmica entre desenvolvimento humano e Corporeidade, bem como assume a importância da percepção para o entendimento de Motricidade e de Corporeidade.

Ao olharmos a Motricidade na perspectiva de área de conhecimento científico nos damos conta que ela valoriza não apenas os fatos, locus de análise da ciência tradicional, mas pressupõe que em todo fato há valores, destinando grande atenção aos aspectos axiológicos.

A Motricidade como possibilidade de ciência possibilita um novo status para a Educação Física, elevando-a na consistência epistemológica. O próprio Sergio (1996, p. 126) é quem nos informa: 
Seja como for, é bem evidente que a Educação Física (enquanto macro conceito) é tão só uma tradição disciplinar, não uma autonomia disciplinar. Como tradição disciplinar pode ser ensinada, mas sem autonomia disciplinar dificilmente se investiga e se constitui em comunidade científica. A Educação Física nunca precisou de autolegitimar-se epistemologicamente, ou seja, de encontrar em si as formas e as razões de sua própria cientificidade, precisamente porque o Poder sempre se serviu dela e nunca a serviu como instrumento insubstituível de conhecimento e transformação.

Trovão do Rosário (2008, p. 35), se referindo à Motricidade como área de conhecimento científico, alerta-nos que "[...] a Motricidade Humana tem que gerar cultura fundada mais na sabedoria do que no saber muitas coisas". Isto provoca uma mudança de paradigma para a área, pois a Educação Física tradicional servia para tudo, mas, ao mesmo tempo, não representava nada enquanto ciência autônoma. Este autor lembra de uma publicação editada pela Comissão de Reforma do Sistema Educativo de Portugal onde encontramos:

A motricidade é intencionalidade operante: partindo do corpo próprio, sublinha não haver significação que não se refira ao corpo, nem sentido que o corpo não realize e manifeste", e ainda que "A motricidade humana, partindo do estritamente corpóreo, alarga-se até à pesquisa da percepção, entendida esta como consciência de uma articulação corpo-mundo; mantém, assim, a regulação, a execução e a integração do comportamento e traduz a apropriação da cultura e da experiência (TROVÃO DO ROSÁRIO, 2008, p. 43-44).

Como mencionamos na introdução, buscamos associar Motricidade à Corporeidade e ambas já se fazem presentes nas preocupações dos autores mencionados ao dedicarem-se estabelecer as novas bases epistêmicas para a área da Educação Física.

Se até aqui a proposta dos autores centra-se na Motricidade enquanto conhecimento científico, fator determinante para a identidade da área, a nós, no presente escrito, interessa mais focar sua associação com a Corporeidade debaixo do pressuposto da educação.

O ser humano, diferentemente de outros seres vivos, ao produzir história e cultura, estabelece o tempo vivido na íntima relação com o seu meio, e ao relacionar-se com outros seres humanos e com o universo desencadeia o processo educativo. Assim, se pensarmos na educação como uma possibilidade da instruir o homem como um todo, fatalmente teremos que elaborar processos de aprendizagem para esse todo.

O conhecimento do homem tem sempre origem no corpo, assim como também o conhecimento do mundo parte do corpo. O que caracteriza o humano é precisamente sua capacidade relacional com outros seres, demandando isto a vivência da Motricidade.

Existencializar a Motricidade demanda ir ao encontro de nossas diferenças. "A riqueza do processo educativo reside em larga medida no facto de, felizmente, de sermos todos diferentes" (TROVÃO DO ROSÁRIO, 2008, p. 53).

A passagem do sentido do movimento historicamente presente na Educação Física, momento em que se discutia com grande ardor se educávamos pelo movimento ou para o movimento, para a intencionalidade presente na Motricidade, foi um passo significativo para o entendimento do humano no homem.

Trigo (1999, p. 90) nos lembra que o homem, "[...] como ser biológico, nasce com as capacidades que lhe permitem cumprir com suas necessidades básicas" e por essa razão realiza movimentos. Já em seu processo de humanização encontramos a intencionalidade, elemento este que propicia ao homem dar significado ao ato de se 
movimentar, contando para isso com seu raciocínio, sua sensibilidade e afetividade, assim como sua criatividade.

A mesma autora revela a transformação do simples movimento em atos de criação, qualidade da Motricidade, e esta necessariamente exige relações entre humanos que se comunicam e se socializam (TRIGO, 1999).

Quando trazemos a relação corpo, movimento, Motricidade, Corporeidade, associando isso à consciência, calcados em Merleau-Ponty (2011, p. 159) temos "[...] todo movimento é indissoluvelmente movimento e consciência do movimento", lembrando que consciência para o autor é um ato de alerta corporal e não simplesmente mental.

Isto remete ao trabalho de Elenor Kunz o primeiro teórico da área da Educação Física no Brasil a propor uma abordagem fenomenológica do se-movimentar humano. Nesta proposta estão inscritos pressupostos da Motricidade, porque diferentemente de outras propostas construídas para a área como abordagens morfológica, biomecânica, empírico-analítica do ato motor e outras, todas centradas em observar o movimento humano a partir de fora, a abordagem fenomenológica do se-movimentar constrói pontes entre o externo e o interno através da intencionalidade e da percepção do movimento (KUNZ; MARQUES, 2019).

Mais recentemente Moreira e Simões (2018, p. 168) procurando associar os sentidos de Motricidade ao humanismo e ao esporte destacam:

[...] a estruturação do ser é tida como uma unidade existencial dotada de movimento para progredir, permanentemente, no conhecimento de si, dos outros e do mundo. Movimentar-se também é uma das principais características do esporte, razão pela qual podemos integrar os sentidos do esporte, corporeidade e vida na busca de um redimensionamento do humanismo moderno.

Desenvolver os sentidos da Motricidade pode nos levar a reconhecer, como indica Inforsato (2006, p. 97) que "[...] essa visão de mundo acoplada ao empirismo, que em síntese busca os elementos de prova da verdade nos fatos, consolidou a forma de parte considerável dos europeus entender o mundo e estimar a vida". Como isso tudo pode ser esquadrinhado, analisado e previsto, o movimento humano só se justifica no sentido de produção, competição e consumo.

Freire (2008, p. 53), com toda razão, lembra que a educação brasileira é resultante dos valores europeus e isto está ainda impregnado em nossa cultura. Tanto a educação de forma geral, quanto a Educação Física, chegaram para serem consumidas. Talvez por isso o corpo ter sido destinado a uma posição secundária, ganhando a primazia a educação intelectiva e, consequentemente, esta não pode reconhecer o corpo que somos.

\footnotetext{
Trata-se, antes de tudo, de afirmar um conceito de vida, uma maneira de viver, uma ética, em oposição a outra, secular, eurocêntrica, cuja raiz é a negação do próprio corpo como entidade de realização da vida. [...] Mais que quaisquer outras, as expressões "meu corpo" e "nosso corpo" indicam que esse corpo se trata de um objeto ao qual alguém, que não é ele, se dirige objetivamente. Vivemos, netas civilização, como se o corpo fosse nosso objeto direto. Ele não é nós, está fora de nós, está à nossa frente, nos pertence.
}

Se isto persiste até hoje, produções a respeito de Motricidade e de Corporeidade não têm o menor sentido. Não nos espanta estes temas só aportarem entre nós a partir da segunda metade do século XX. No entanto, o mesmo autor mencionado insiste em afirmar que a "Motricidade é a dinâmica de realização da vida corporal que somos; é o 
modo como a vida que, em dado momento, somos nós se manifesta neste mundo" (FREIRE, 2008, p. 63).

A importância de vivenciar valores e atitudes presentes nos pressupostos de Motricidade possibilitam entender a educação enquanto destinar-se a ensinar os seres humanos serem eles mesmos, o que certamente colaboraria para entendermos e vivermos em democracia, objetivo um tanto utópico nos dias atuais em nosso país. Viver em relação com outros em democracia exige o reconhecimento de que somos seres corpóreos e não apenas intelectivos.

Afinal, Motricidade Humana possibilita uma nova visão de homem que se movimenta e com isto novos contornos éticos, estéticos e educacionais, todos presentes na responsabilidade da Educação e da Educação Física enquanto epistemes e enquanto fomentadoras de teorias pedagógicas.

\title{
CORPOREIDADE: SEU LUGAR É TAMBÉM NA ESCOLA
}

Perceber é tornar presente qualquer coisa com a ajuda do corpo

(Maurice Merleau-Ponty)

Um primeiro alerta é necessário para não cairmos em um erro interpretativo ou mesmo para não passarmos a ideia de um idealismo ingênuo. O tema Corporeidade não é objeto de estudo de nenhuma área de conhecimento em especial. Ele está mais centrado em dimensões axiológicas e existenciais do que em definições conceituais ou dogmatismos estéreis. Para nós, Corporeidade diz mais respeito à atitude do que a conceito. E mais ainda, Corporeidade engloba o sensível, o inteligível e a Motricidade.

Também como argumentação inicial poderíamos perguntar: Por que a necessidade de darmos espaços para estudos e pesquisas sobre Corporeidade? Sem dúvida, elaborar reflexões a respeito da Corporeidade possibilita enfrentar as preocupações de Foucault expressas no escrito de Gallo e Zeppini (2016, p. 110):

\begin{abstract}
A modernidade descobre o corpo como objeto do poder e o filósofo nos apresenta as tecnologias de produção do indivíduo produtivo, base do sistema capitalista, que foram centradas nas instituições disciplinares: as escolas, as prisões, os hospitais, as fábricas. A disciplina, por meio da "docilização dos corpos", moldou o homem moderno, operando nesse duplo registro de produção de um corpo inteligível, por um lado, e útil e produtivo, por outro.
\end{abstract}

Claro está que a vertente do corpo útil e produtivo predomina nos tempos atuais, considerando que numa cultura de consumo, hegemônica entre nós, o corpo é "[...] veículo de prazer, estando ligado a imagens idealizadas de saúde, juventude, beleza e aptidão, maximizando o aparecimento das indústrias de moda, cosméticos, alimentação, academias de ginástica, cirurgias plásticas...", como o revelado por Moreira e Simões (2016, p. 135).

Daí a importância do estudo da Corporeidade considerando que ela traz para nossa aprendizagem termos como sentir, sonhar, transcender, criar, palavras essas de grande importância para o entendimento do humano no homem. O tema Corporeidade trabalhado nos meios acadêmicos permite, dentre outras argumentações: reflexões questionadoras da vida calcada no consumismo; aclaramento de que possuímos uma perspectiva instrumental de corpo e vida; questionamentos de atitudes corruptoras as quais acabam justificando uma sociedade corrupta (MOREIRA; SIMÕES, 2016). 
Nóbrega (2010, p. 11) ao propor uma fenomenologia do corpo estruturada em Merleau-Ponty, indica a importância do tema Corporeidade ser trabalhado no universo acadêmico, pois isto contribuiria para a superação da ideia de corpo máquina, argumentando que assim agindo teríamos enfatizando outra leitura de corpo, na qual estivessem presentes possibilidades diferentes de perceber o mundo, os objetos e as pessoas. "É a realidade do corpo que nos permite imaginar, sonhar, desejar, pensar, narrar, conhecer, escolher."

Nesta trilha o corpo é muito mais que a justaposição de órgãos e o ato de perceber ganha novas dimensões e a significação do mundo parte do corpo e não da ordem de conceitos. "A percepção está relacionada ao movimento, à atitude corporal." (NÓBREGA, 2010, p. 70).

Outro argumento que podemos indicar para a importância da reflexão sobre o tema Corporeidade na relação com a Motricidade, especialmente relevante para os dias atuais em nossas relações sociais, pode ser encontrado em Le Breton (2013, p. 129):

\begin{abstract}
Superequipados com meios que lhe permitem comunicar-se sem precisar deslocar-se (telefone, celular, e-mail, internet etc.) o indivíduo não precisa mais, necessariamente, se encontrar fisicamente com outros; a conversa frente a frente durante um passeio tranquilo ou em um lugar silencioso parece hoje perder espaço diante do diálogo apaixonado do proprietário de um celular ou computador com seus interlocutores invisíveis e falantes. As incontáveis conversas virtuais, frágeis e efêmeras, são hoje sintomas das carências do vínculo social, indicam uma sede de contato e, ao mesmo tempo, uma preocupação de preservar-se, de não se comprometer demais.
\end{abstract}

Reflexões e produção de conhecimentos sobre Corporeidade colaboram para o esforço de compreender corpo não apenas algo acessório do processo educacional e das propostas pedagógicas no interior da escola, condição esta ainda predominante em nossos bancos escolares.

Toda essa relação Motricidade e Corporeidade torna-se importante se considerarmos que a percepção emerge da Motricidade assim como a cognição emerge da Corporeidade (NÓBREGA, 2016).

Toda a argumentação até aqui desenvolvida justifica o indicado inicialmente, que Corporeidade, sob a perspectiva dos pressupostos epistemológicos da fenomenologia, não é apenas um conceito e sim uma atitude calcada na existencialidade do sujeito. Afinal, Merleau-Ponty (2011, p. 14) já afirmava: "O mundo é não aquilo que eu penso, mas aquilo que eu vivo; eu estou aberto ao mundo, comunico-me indubitavelmente com ele, mas não o possuo, ele é inesgotável".

Corpo, Corporeidade, Motricidade, movimento ganharam novas dimensões a partir de Merleau-Ponty, inclusive porque esse pensador também associa tais termos como consciência, vivência e mundo (MOREIRA, 2019).

Ainda nesta trilha, Corporeidade pode permitir que interpretemos o mundo mais do que o expliquemos, permite pensar o outro e a si mesmo a partir da significância dessa relação.

Trabalhar o tema Corporeidade em cursos de graduação, por exemplo, pode propiciar o entendimento de que:

[...] a corporeidade é, existe e possui, através da cultura, significado. Daí a constatação de que a relação corpo-educação, por meio da aprendizagem, significa aprendizagem da cultura - dando ênfase aos sentidos dos acontecimentos -,e aprendizagem da história - enfatizando aqui a relevância das ações humanas. Corpo que se educa é corpo humano que aprende a fazer história e cultura (MOREIRA, 2012, p. 135). 
Adentrando ao espaço escolar, percebemos a evolução tecnológica presente nas salas de aula. Alguns exemplos dessa afirmação:

Quadro 1: Evolução tecnológica na escola.

\begin{tabular}{|l|l|l|l|}
\hline Recursos Didáticos & $\begin{array}{l}\text { Primeira Metade } \\
\text { do Século XX }\end{array}$ & $\begin{array}{l}\text { Segunda Metade } \\
\text { do Século XX }\end{array}$ & Século XXI \\
\hline Áudio Visuais & Quadro de Giz & $\begin{array}{l}\text { Quadro de Giz } \\
\text { Retroprojetor } \\
\text { Projetor de Slides }\end{array}$ & $\begin{array}{l}\text { Quadro Branco } \\
\text { Data Show } \\
\text { Internet }\end{array}$ \\
\hline Caneta do Aluno & $\begin{array}{l}\text { Caneta de Pena e e } \\
\text { Tinteiro na Carteira }\end{array}$ & $\begin{array}{l}\text { Caneta Bic várias cores } \\
\text { Faneta Bic } \\
\text { Celulares }\end{array}$ \\
\hline Fontes de Consulta & $\begin{array}{l}\text { Tesouro da Juventude e } \\
\text { Enciclopédias }\end{array}$ & $\begin{array}{l}\text { Livros do Professor } \\
\text { Caderno do Aluno } \\
\text { Padronizado }\end{array}$ & $\begin{array}{l}\text { Google com Material } \\
\text { Online }\end{array}$ \\
\hline CORPO DO ALUNO & Quietos em colunas & Quietos em colunas & Quietos em colunas \\
\hline
\end{tabular}

Fonte: os autores, 2019.

Como nesta simples demonstração, constata-se que no interior da escola o trato com o corpo do aluno não evoluiu, havendo a manutenção de uma educação centrada na disciplina corporal. Claro está que o paradigma cartesiano de uma educação intelectiva e não de corpo inteiro ainda está hegemônico.

Ao nos aprofundarmos ainda nos escritos de Merleau-Ponty constatamos que sua previsão de superação do paradigma cartesiano, feita na primeira metade do século passado, ainda não se encontra presente na formação profissional dos graduados em cursos de licenciatura em geral, inclusive na Educação Física (MOREIRA, 2019).

\footnotetext{
Nosso século apagou a linha divisória entre o "corpo" e o "espírito" e vê a vida humana como espiritual e corporal de parte a parte, sempre apoiada no corpo sempre associada, até nos seus modos mais carnais, às relações das pessoas. Para muitos pensadores, no fim do século XIX, o corpo era um pedaço de matéria, um feixe de mecanismos. O século XX restaurou e aprofundou a noção de carne, ou seja, de corpo animado (MERLEAUPONTY, 1991, p. 256).
}

Professores de forma geral, e em especial os da Educação Física, necessitam redimensionar o trato do corpo de seus alunos. Corpo não é uma "coisa" a ser manipulada e seus movimentos não devem ser interpretados apenas com o princípio mecânico. O corpo que se move é o mesmo, por exemplo, que se apaixona e movimento e paixão também estão presentes no sentido da Corporeidade e da Motricidade (MOREIRA et al., 2008).

Pior ainda a situação hoje encontrada em muitas escolas, nas quais a vigilância corporal está explícita, inclusive no interior das salas de aula, controlando movimentos de alunos e professores.

O corpo nos momentos atuais passou a ser fortemente vigiado, inclusive nas preocupações, como por exemplo, com a qualidade de vida. "A retórica contemporânea da saúde e do corpo saudável fundam-se num princípio articulado de vigilância e controle, diagnóstico e terapia." Diz mais Silva (2008, p. 114): "Vigilância bioquímica e imagética versus controle terapêutico".

Motricidade e Corporeidade são, assim, temas indispensáveis a serem trabalhados enquanto conhecimento nas áreas pedagógicas e nos cursos de licenciatura de forma geral. 


\section{TEORIA DA COMPLEXIDADE COLABORANDO COM A INTERCULTURALIDADE}

O conhecimento deve saber contextualizar, globalizar, multidimensionalizar, ou seja, ser complexo. É preciso inserir os conhecimentos parciais e locais no complexo e no global, sem esquecer as ações do global sobre o parcial e local.

(Edgar Morin)

Neste momento do escrito vamos tangenciar o tema interculturalidade com a teoria da Complexidade estruturada por Edgar Morin, procurando nessa tarefa identificar relações com Motricidade e Corporeidade. E é aqui também a necessidade de realçar o contexto do hemisfério sul, afinal a quase totalidade dos países que proferem sua fala e sua escrita em língua portuguesa estão aqui localizados.

Afinal, em quais países ou regiões administrativas nosso idioma se acha presente? Neste item estamos bem representados através de: Angola / Brasil / Cabo Verde / Guiné Bissau / Guiné Equatorial / Macau / Moçambique / Portugal / São Tomé e Príncipe / Timor-Leste.

Daí uma primeira constatação. Aglutinar pesquisa na perspectiva de internacionalização, via de regra, a referência nos países do hemisfério sul é juntar conhecimentos com países do hemisfério norte. Dificilmente temos grandes relações no sentido sul/sul. É necessário superar esta história acadêmica de dependência do conhecimento dos países do norte.

Identificada a região geográfica, vamos a outro princípio norteador: qual o sentido educacional balizador do nosso trabalho acadêmico? Aqui entra o pensamento de Morin (2000) com sua Teoria da Complexidade, a partir da qual podemos estabelecer diretrizes para o diálogo sul/sul, sempre buscando respeitar as especificidades, mas caminhando para encontrar elementos que nos unem. Necessitamos aprender a ser, a conhecer, a fazer e a viver juntos, estabelecendo políticas educacionais significativas para nossos países.

Um primeiro princípio a ser seguido na trilha da interculturalidade pode ser encontrado no que Morin (2000, p. 15) denomina de ensinar a condição humana.

\footnotetext{
O ser humano é a um só tempo físico, biológico, psíquico, cultural, social, histórico. Esta unidade complexa da natureza humana é totalmente desintegrada na educação por meio das disciplinas, tendo-se tornado impossível aprender o que significa ser humano. É preciso restaurá-la, de modo que cada um, onde quer que se encontre, tome conhecimento e consciência, ao mesmo tempo, de sua identidade complexa e de sua identidade comum a todos os seres humanos.
}

Reconhecer a condição humana dos habitantes do hemisfério sul é estar em sintonia com as diferenças, mas estas de maneira nenhuma deve impedir a busca de nossa unidade. "A compreensão mútua entre os seres humanos, quer próximos, quer estranhos, é daqui para frente vital para que as relações humanas saiam de seu estado bárbaro de incompreensão." (MORIN, 2000, p. 17).

Há de se caminhar no que Morin (2013, p. 57) indica na direção de uma política da humanidade e para isto é necessário reconhecer as diversidades culturais e nacionais. Precisamos nos ater à "[...] preocupação de salvaguardar indissoluvelmente a UNIDADE/DIVERSIDADE humana: o tesouro da unidade humana é a diversidade humana, o tesouro da diversidade humana é a unidade humana". 
Pleitear a interculturalidade de nossos povos demanda o entendimento de desenvolvimento para além da diretriz econômica. Mais uma vez recorrendo a Morin (2013, p. 59), necessitamos de uma política da humanidade e esta:

[...] deverá deixar em segundo plano o elemento negativo, que hoje ocupa o primeiro plano, ou seja, a hegemonia do lucro, a redução política à economia, a redução do conhecimento ao cálculo (que ignora a multidimensionalidade da existência humana), o domínio da racionalização (que descarta tudo o que escapa à sua lógica fechada) [...] Por isso mesmo, a política da humanidade implica o respeito aos saberes, aos fazeres, às artes de viver das diversas culturas, inclusive as orais.

Estamos dispostos a isto nas nossas relações culturais, educacionais e acadêmicas no espaço geográfico sul/sul? Se houver essa vontade, muito pode ser feito no propósito da interculturalidade.

Para tanto há que se estabelecer uma educação centrada na aprendizagem humana e humanizante, por isso mesmo significativa, alcançada se considerarmos educação como aprendizagem da cultura (REZENDE, 1990).

\section{CONSIDERAÇÕES FINAIS}

Associar os temas Motricidade, Corporeidade e Complexidade buscando refletir sobre interculturalidade no espaço geográfico do hemisfério sul, é missão possível a partir de um novo olhar para a educação, buscando superar o paradigma tradicional que trata corpo como objeto e de forma mecânica.

Pelo exposto ao longo de nossa argumentação, tais temas só poderão ser integrados a partir de uma mudança paradigmática e não apenas com alterações programáticas, daí a importância do estudo da Teoria da Complexidade.

Motricidade e Corporeidade exigem que nos dediquemos a estudar a obra de Morin (2000, p. 106), especialmente nas argumentações ligadas à antropo-ética para: "[...] alcançar a unidade planetária na diversidade; respeitar no outro, ao mesmo tempo, a diferença e a identidade quanto a si mesmo; desenvolver a ética da solidariedade; desenvolver a ética da compreensão; ensinar a ética do gênero humano".

Eis a missão que nos move a caminhar.

\section{REFERÊNCIAS}

FREIRE, J. B. Um mundo melhor, uma outra educação física. In: RODRIGUES, D. (Org.). Os valores e as atividades corporais. São Paulo: Summus, 2008. p. 51-74.

GALLO, S.; ZEPPINI, P. S. "O que pode um corpo?": perspectivas filosóficas para a corporeidade. In: MOREIRA, W. W; NISTA-PICCOLO, V. L. (Orgs.). Educação física e esportes no século XXI. Campinas: Papirus, 2016. p. 107-131.

INFORSATO, E. C. A educação entre o controle e a libertação do corpo. In: MOREIRA, W. W. (Org.). Século XXI: a era do corpo ativo. Campinas: Papirus, 2006. p. 91-108.

KUNZ, E.; MARQUES, D. A. P. A educação física vista pela fenomenologia. In: NÓBREGA, T. P.; CAMINHA, I. O. (Orgs.). Merleau-Ponty e a educação física. São Paulo: Liber Ars, 2019. p. 39-55.

LE BRETON, D. Adeus ao corpo. In: NOVAES, A. (Org.). O homem-máquina: a ciência manipula o corpo. São Paulo: Companhia das Letras, 2013. p. 123-137. 
MERLEAU-PONTY, M. Fenomenologia da percepção. São Paulo: Editora WMF Martins Fontes, 2011. MERLEAU-PONTY, M. Signos. São Paulo: Martins Fontes, 1991.

MOREIRA, W. W. Formação profissional em ciência do esporte: homo sportivus e humanismo. In: BENTO, J. O.; MOREIRA, W. W. Homo sportivus: o humano no homem. Belo Horizonte: Instituto Casa da Educação Física, 2012. p. 112-180.

MOREIRA, W. W. Merleau-Ponty na sala de aula e na beira do campo: contribuições para a área da educação física / esportes. In: NÓBREGA, T. P.; CAMINHA, I. O. Merleau-Ponty e a educação física. São Paulo: LiberArs, 2019, p. 21-38.

MOREIRA, W. W.; PORTO, E. R. T.; CARBINATTO, M.; SIMÕES, R. Do corpo à corporeidade: a arte de viver o movimento no esporte. In: RODRIGUES, D. (Org.). Os valores e as atividades corporais. São Paulo: Summus, 2008. p. 127-146.

MOREIRA, W. W.; SIMÕES, R. Esporte e humanismo. In: SILVA, J. V. P.; MOREIRA, W. W. (Orgs.). Lazer e esporte no século XXI: novidades no horizonte. Curitiba: InterSaberes, 2018. p. 161-177.

MOREIRA, W. W.; SIMÕES, R. Educação física, esportes e corporeidade: associação indispensável. In: MOREIRA, W. W.; NISTA-PICCOLO, V. L. (Orgs.). Educação física e esportes no século XXI. Campinas: Papirus, 2016. p. 133-149.

MORIN, E. A via para o futuro da humanidade. Rio de Janeiro: Bertrand Brasil, 2013.

MORIN, E.. Os sete saberes necessários para a educação do futuro. São Paulo: Cortez; Brasília: Unesco, 2000.

NÓBREGA, T. P. Corporeidades...: inspirações merleau-pontianas. Natal: Editora do IFRN, 2016.

NÓBREGA, T. P. Uma fenomenologia do corpo. São Paulo: Editora Livraria da Física, 2010.

REZENDE, A. M. Concepção fenomenológica da educação. São Paulo: Cortez / Autores Associados, 1990.

SERGIO, M. Epistemologia da motricidade humana. Lisboa: Faculdade de Motricidade Humana, 1996.

SILVA, P. S. Corpo, vigilância, controle. In RODRIGUES, D. (Org.). Os valores e as atividades corporais. São Paulo: Summus, 2008. p. 113-126.

TRIGO, E. Creatividad y motricidade. Barcelona: Inde Publicaciones, 1999.

TROVÃO DO ROSÁRIO, A. A motricidade humana e a educação. In: SERGIO, M. (Org.). O sentido e a acção. Lisboa: Instituto Piaget, 2008. p. 31-60.

Recebido em: 31 out. 2019.

Aprovado em: 05 dez. 2019. 